\title{
Coregistration and Fusion: An Easy and Reliable Method for Identifying Cranial Nerve IV on MRI
}

W e read with much interest the article by Bunch et $\mathrm{al}^{1}$ in the March 2017 issue of the American Journal of Neuroradiol$o g y$, in which they described the trochlear groove and trochlear cistern as reliable anatomic landmarks when searching for the tentorial segment of cranial nerve IV on MR imaging. The authors provided useful indications to recognize these 2 structures with a T2-weighted driven equilibrium radiofrequency reset pulse sequence. Confirming these 2 landmarks was significantly associated with correctly identifying the trochlear nerve.

We agree that short sequences are more practical for routine clinical use as opposed to those previously reported in the literature using high-resolution motion-sensitized driven equilibrium sequences with a 26-minute acquisition time. ${ }^{2}$ This sequence use is particularly true for cranial nerve IV imaging because a substantial number of patients being evaluated for suspected trochlear nerve pathology, including congenital palsy, are children, who are more prone to movements than adults. Therefore, a long scanning time may exacerbate motion artifacts on MR images.

However, we believe that this study has a few limitations that may impair its scope. The trochlear nerve remains the thinnest of all cranial nerves, with a mean diameter of approximately $0.5 \mathrm{~mm}$ (range, $0.3-0.9 \mathrm{~mm}$ ). It has a complex course around the midbrain and is in close proximity to many arteries and veins with similar courses and calibers. The voxel size acquired in this study ranged from $0.3 \times$ $0.35 \times 3.0$ to $0.4 \times 0.44 \times 3.0$; thus, the section thickness (resolution of the z-axis) provided was $3.0 \mathrm{~mm}$, which is too large to identify the trochlear nerve consistently. Moreover, the gap ranged from 0.3 to 1 $\mathrm{mm}$, which is too high to observe a $0.5-\mathrm{mm}$ structure. ${ }^{3}$ Much thinner sections are required to visualize the trochlear nerve, with a maximum of $0.25-\mathrm{mm}$ section thickness and no gap.

The imaging findings of this study remain subjective and are not supported by surgical or pathologic correlations. Additionally, significant discrepancies between the MR imaging and anatomic findings were reported in cadaveric studies. Our colleagues' images are somewhat noisy, with CSF flow-related artifacts and are therefore not very convincing, even with annotations.

An interesting option for reliably identifying cranial nerve IV on MR imaging within a reasonable acquisition time may be the use of

http://dx.doi.org/10.3174/ajnr.A5286

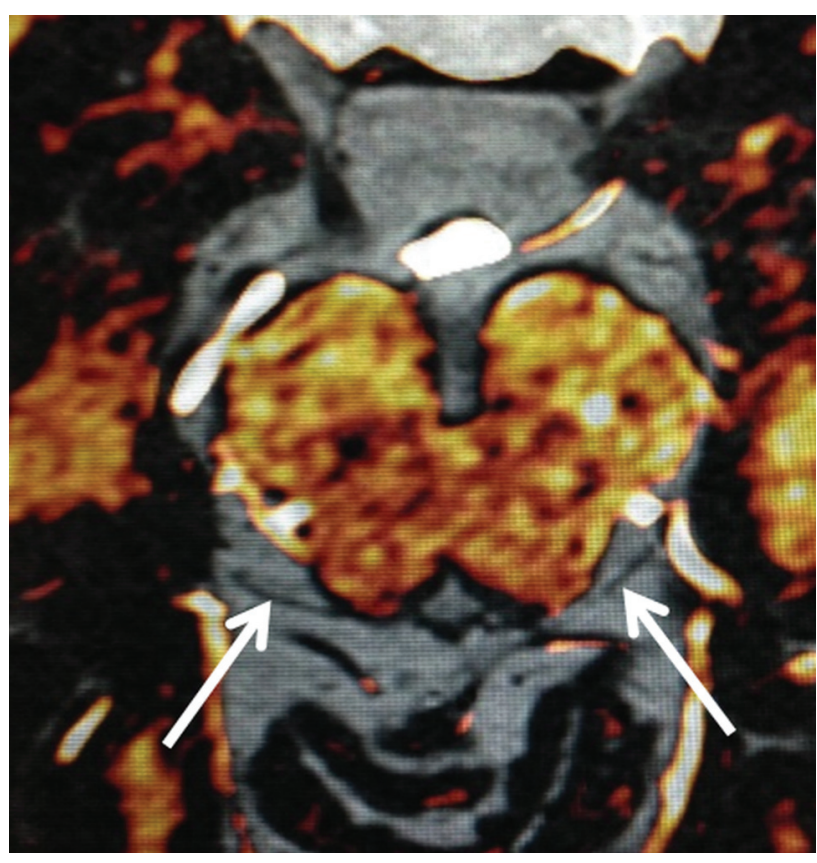

FIGURE. Coregistration-fusion of an MR angiography and a T2weighted driven equilibrium radiofrequency reset pulse sequence allowing to distinguish cisternal vessels colored in white from the trochlear nerves in black (arrows).

coregistration and fusion ${ }^{4}$ of an MR angiography sequence and of a "routine" T2-weighted driven equilibrium radiofrequency reset pulse sequence. Regrettably, even a very high resolution may still be insufficient due to the very complex course of the nerve and its close proximity to adjacent vessels. MRA enables the reader to clearly and reliably identify both arteries and veins, despite their highly variable anatomy. Therefore, this technique supports correct identification of the closely related trochlear nerve (Figure). This method is easy and is available in various software packages. A long posttreatment process is not necessary, and it can be performed during routine clinical practice in many institutions without involving highly specialized providers. With this method, all segments of the trochlear nerve are visible, especially its tentorial segment where the nerve is parallel to the vessels and runs along the tentorial edge. This approach may also be used successfully on larger cranial nerves such as the oculomotor or the abducens nerves.

AJNR Am J Neuroradiol 38:E81-E82 Oct 2017 www.ajnr.org

E81 
Finally, it is possible that the key for reliable and accurate identification of the trochlear nerve may be the use of a simple coregistration and fusion instead of long and complex high-resolution MR imaging acquisitions.

Disclosures: Julien Savatovsky — UNRELATED: Consultancy: Servier International Research Institute (IRIS), Madday Pharmaceutical, Bristol-Myers Squibb, GlaxoSmithKline, Comments: All except IRIS paid me around $\$ 50002$ years ago*; Expert Testimony: Philips Healthcare, Bayer Pharmaceutical; Grants/Grants Pending: Association de la Recherche Sur le Syndrome Immuno-Déficitaire Acqui*; Payment for Lectures Including Service on Speakers Bureaus: Philips Healthcare, IRIS, Biogen; Travel/Accommodations/Meeting Expenses Unrelated to Activities Listed: GE Healthcare, Philips, Bayer. *Money paid to the institution.

\section{REFERENCES}

1. Bunch PM, Kelly HR, Zander DA, et al. Trochlear groove and trochlear cistern: useful anatomic landmarks for identifying the tentorial segment of cranial nerve IV on MRI. AJNR Am J Neuroradiol 2017;38: 1026-30 CrossRef Medline

2. Kanoto M, Toyoguchi Y, Hosoya T, et al. Visualization of the trochlear nerve in the cistern with use of high-resolution turbo spin-echo multisection motion-sensitized driven equilibrium. AJNR Am J Neuroradiol 2013;34:1434-37 CrossRef Medline

3. Choi BS, Kim JH, Jung C, et al. High-resolution 3D MR imaging of the trochlear nerve. AJNR Am J Neuroradiol 2010;31:1076-79 CrossRef Medline

4. Liu P, Eberhardt B, Wybranski C, et al. Nonrigid 3D medical image registration and fusion based on deformable models. Comput Math Methods Med 2013;2013:902470 CrossRef Medline

(1) A. Lecler

(D). Savatovsky

Department of Radiology

(1) F. Audren

Department of Ophthalmology Fondation Ophtalmologique Adolphe de Rothschild

Paris, France 